\title{
FORMATIVE ASSESSMENT IN THE ENGLISH AS A FOREIGN LANGUAGE CLASSROOM IN SECONDARY SCHOOLS IN POLAND. REPORT ON A MIXED-METHOD STUDY.
}

\author{
MAŁGORZATA BARAN-ŁUCARZ \\ University of Wrocław; Institute of English Studies \\ ul. Kuźnicza 22, 50-138 Wrocław, Poland \\ E-mail address: malgorzata.baran-lucarz@uwr.edu.pl \\ ORCID: https://orcid.org/0000-0001-9310-0606
}

\begin{abstract}
Aim. The paper addresses the problem of formative assessment in the foreign language (FL) classroom. Its main objective is to present the outcomes of a study identifying tendencies related to the use of formative assessment during English lessons in Polish high schools, and students' opinions on the frequency, type and effects of assessment they had been provided with during secondary school education.

Methods. The data come from a retrospective study applying a mixed-method approach. They were gathered with a questionnaire based on a Likert scale, complemented with a few open-ended questions. The responses were provided by 106 students who graduated various high schools in the years 2014-2017 in 36 towns/cities located in different regions of Poland. The frequencies of using formative assessment in the case of all the FL skills and subskills are presented in comparison to summative assessment. The qualitative data were coded with an aim of finding some common trends.

Results. The study showed that in the case of the participants of this research, formative assessment in secondary education at EFL classes was evidently neglected. Many students (approximately 25\%) acknowledged never having been provided with formative assessment with regards to pronunciation, receptive and productive skills. The open responses signal students' awareness of the importance of feedback and of several negative effects resulting from the lack of its regular provision.

Conclusions. The data gathered in the study seem to call for the need to raise the understanding of the role and the practical abilities to use formative assessment in the EFL classroom both at pre-service and in-service teacher training courses.

Key words: formative assessment, Polish EFL context, secondary school education, mixed-method approach
\end{abstract}




\section{INTRODUCTION}

Specialists in education all agree that assessment constitutes a crucial eleSment of the didactic process. As Paul Black and Dylan Wiliam (2006, p. 9) claim, it is meant to "first and foremost, serve the purpose of supporting learning," making it visible what students have already managed to learn and what the further areas of focus should be. Where assessment in education is concerned, several types have been identified, such as formative vs. summative, formal vs. informal, and explicit vs. implicit, which can be compared with regard to their functions and which have been evaluated in terms of the benefits they bring to the learning and teaching processes (see Brown, 2004; Harris, \& McCann, 1994).

In recent years, the assessment type that has captivated most attention among educational researchers is formative assessment (FA), which is due to the positive direct and indirect effects it has been found to have on the process and outcomes of learning various subjects (Black, \& Wiliam, 1998a; Crooks, 1988; Fontana, \& Fernandes, 1994). Its vital positive effects have been noted, among others, in the area of foreign language (FL) learning and teaching (Bachman, 1990; Bachman, \& Palmer, 1996; Brown, 2004; Gattullo, 2000; Radford, 2015). Having been introduced into the Polish education system almost 20 years ago, it could be expected to have found a safe ground and to be used on a regular basis by Polish teachers. Is it indeed so? The paper offers a look at this matter, providing data regarding the use of formative assessment during classes of English as a FL (EFL) in Polish high schools. The paper opens with a brief introduction of formative assessment contrasted with summative assessment, with a particular focus on its use in the FL classroom and on a project consisting in introducing FA into the Polish education system. What follows is a report on a study conducted among Polish graduates of numerous high schools, starting with the methodology of the research - research questions, participants, instruments, data gathering and analysis procedures - followed by the presentation and discussion of its quantitative and qualitative results. The paper closes with conclusions, a critical look at the study and very brief practical implications deriving from the outcomes of the reported research.

\section{FORMATIVE ASSESSMENT VS. SUMMATIVE ASSESSMENT}

According to Domingos Fernandes (2011), the terms summative and formative assessment can be traced back to 1960s. However, initially, they were used in reference to educational programs rather than to the evaluation of the learning progress of students. Although 10 years later the area of assessment shifted from programs to the process of learning, evaluation would be rare (usually at the end of some program), with the main matter of focus still being learning outcomes. It is not earlier than in the 1980s that assessment began concentrating on the process of learning, taking the form of 
"continuous" and "interactive" assessment, requiring active involvement of the learners (Barbosa, \& Beserra, 2015, p. 102), giving the beginnings of true formative assessment.

To ensure a better understanding of the features and functions of formative assessment, it is worth comparing it to another type of evaluation, namely summative assessment. Following J. Myron Atkin, Black and Janet Coffey (2001), Brian W. Radford (2015, p. 8) states that the primary objective of the latter is to "measure learning and to make informed inferences about the learner's ability or level of achievement" (Atkin et al., 2001). As the name suggests, it would usually sum up and finalize some stage of learning, verifying the knowledge and/or skills students managed to master during a particular period of time (Brown, 2004). The outcome of such assessment is usually represented quantitatively in the form of scores, points or percentages. Although learning may be a "secondary benefit as a result of taking a summative assessment" (Radford, 2015, p. 8), traditionally it is not complemented with any extra feedback provided to the students. Despite the fact that it usually leads to high levels of anxiety (see Alderson, Brunfaut, \& Harding, 2015), which can negatively influence performance, it is commonly used in education due to it being relatively easy to design and administer, and to it being required and needed as a formal type of assessment by educational institutions.

As several educational researchers claim, assessment of learning, which summative assessment can be associated with, calls for the need to be complemented by assessment for learning: the primary characteristic of formative assessment. As Aimee Lewy (1990) points out, formative assessment lacks a straightforward definition. As indicated earlier, this time the process of learning is superordinate to the final outcome of learning, with the student being perceived as a key figure at the centre of the process, and the questions Why (not)? and How? being at the forefront of every decision taken by the teacher. Explaining the role of formative assessment, Matheus de Almeida Barbosa and Larissa Santos Beserra (2015) note the similarity between the teaching profession and the medical profession. Following this way of thinking, we can compare the teacher to a doctor and the patient to a learner. In order to be successful in curing a patient, a physician needs, first of all, to properly diagnose the illness, by observing the symptoms and by cooperating closely with the patient when gathering necessary information about the health problems. Then the doctor plans the treatment and prescribes medications, usually explaining carefully to the patient his/her strategy, i.e. informing the patient why, how and what is suggested to be done. It is worth stressing that the treatment needs acceptance and understanding of the patient, complemented by his/her trust in the doctor. The results of the treatment are then carefully and constantly observed, so as to be able to take the best-directed decisions on further therapy. Such a cycle-observation, diagnosis, treatment-should also be employed in teaching, with formative assessment being a crucial part of it (Barbosa, \& Beserra, 2015) and the teacher taking analogous steps to those taken by a doctor. Similarly, to make the teaching/learning process effective, the teacher 
must first get to know the interests and targets of the learner, diagnose (assess) his/her strengths and weaknesses, and take them into account when planning with the student how to help him/her achieve the objectives. Introducing the treatment, the teacher provides the learner with continuous feedback, which is the main role of formative assessment (e.g., Fernandes, 2011; Gardner, 2006; Lewy, 1990). What follows is further observation of the results of the introduced guidance and plans for the next steps that could be taken.

According to Anthony J. Nitko (1993), formative assessment has two main purposes, i.e., (1) to choose or, if necessary, modify the learning procedures, and (2) to decide on the best remedies so as to make the learning and teaching processes more effective. Similarly, Francesca Gattullo (2000, p. 279) explains that formative assessment "(a) is an ongoing multi-phase process that is carried out on a daily basis through teacher-pupil interaction, (b) it provides feedback for immediate action, and (c) it aims at modifying teaching activities in order to improve learning processes and results." H. Douglas Brown (2004) pinpoints that most of the assessment taking place in the classroom is actually formative by nature since it allows learners to "form their knowledge by analysing and internalising teachers' comments” (Ketabi, \& Ketabi, 2014, p. 437). Very much in the same vein, the Assessment Reform Group (2007) "defines formative assessment as the process of seeking and interpreting evidence for learners and their teachers to decide where the learners are in their learning, where they need to go, and how best to get there" (Radford, 2015, p. 9).

It is worth adding that formative assessment, just as summative assessment, can be quantitative in nature. What differentiates the two types of assessment is what is done with the gathered data. While the latter uses them to measure/quantify the level of skills and/or knowledge, the former treats them as a source of knowledge on strengths and weaknesses of the learner, leading to feedback provision and clear plans for the nearest future learning aims and methods of realising them (Fernandes, 2011).

\section{BENEFITS OF FORMATIVE ASSESSMENT}

On the basis of literature review of over 250 publications and books reporting on studies examining the effects of formative assessment used when teaching various subjects, P. Black and D. Wiliam (1998a) summarised that "formative assessment yielded greater learning gains than that of conventional teacher-dominant summative assessment practices" (Radford, 2015, pp. 7-8). Several other studies have proven that formative assessment indeed enhances classroom learning (Bachman, 2005; Black, \& Wiliam, 1998a; 1998b; Fontana, \& Fernandes, 1994; Geeslin, 2003; Shohamy, 2001; Van de Watering, \& Van der Rijt, 2006). Since the tasks for formal summative assessment and for giving feedback as part of formative assessment can be analogous, the use of FA has also proven to increase the achievements on formal tests (Brookhart, \& Durkin, 2003; Harlen, \& Winter, 2004). FA has also been found to help teachers deter- 
mine the needs, and long- and short-term goals of their learners (Shohamy, 2001; Triggs, Weeden, Winter, \& Broadfoot, 2000).

FA specialists pinpoint that feedback - the key element of FA-can come from various sources, such as the teacher, a computer (software program) or the student him/herself (Radford, 2015). Research has shown that FA can "empower learners to recognise the areas in which they can improve themselves" (Radford, 2015, p. 6), by raising their self-assessment and self-monitoring skills, which typically leads to more autonomy in learning. In fact, one of the crucial differences between formative and summative assessment is that the former not only allows students to judge their learning outcomes but also promotes it, assuming that with time and practice students will learn to become more accurate in their self-assessment. At the same time, several studies have shown (Butler, \& Jiyoon, 2010; Fontana, \& Fernandes, 1994; McDonald, \& Boud, 2003) that introducing student self-assessment into the didactic process leads to greater learning gains, since the learner becomes more conscious not only of his/her strengths but also lacks of knowledge and difficulties and, consequently, can more effectively plan future work. Very much in the same vein, B. W. Radford (2015) stresses that one of the key roles of formative assessment is to aid students in forming the "index to their learning" (p. 10), by encouraging him/her to ask questions and request help the very moment difficulties with understanding new concepts taught during a lesson appear. Following the conclusions of Arthur W. Chickering and Zelda F. Gamson (1991), B. W. Radford (2015) states that frequent feedback and such constant cooperation between the teacher and student allow both of them "to gain insights on progress during the learning process" and "can keep students on task by helping to identify areas in which the student is not performing well. This prompt feedback informs students while they are planning their individual study plans and strategies" (p. 10).

According to Rick Stiggins (2007), formative assessment aims at making students fully conscious and active participants of the learning process, who on the basis of teacher's assistance should become capable of asking and answering the following questions: "(1) Where am I going? (2) Where am I now? (3) How can I close the gap?" (Radford, 2015, p. 12). To be able to answer question (1), teachers are expected to help the students determine clear learning objectives, by aiding them in identifying their strengths and weaknesses. Responding to question (2) should become possible when the student is provided with regular descriptive feedback, taught how to assess him/herself and how to set learning objects. Finally, the answer to question (3) can be provided when the teacher designs classes that concentrate on developing one aspect at a time, when learners are trained in how to revise and encouraged to practise self-reflection on the learning process and attainments.

Besides FA leading students to become more conscious learners, capable of self-assessing their performance and of reflecting on their process of and progress in learning, it has also been found to affect motivation to learn. For example, Susan M. Brookhart and Daniel T. Durkin (2003) observed that FA correla- 
ted positively with extrinsic and intrinsic motivation. The fact that motivation is one of the strongest predictors of success in, among others, foreign language learning, has been verified in several studies (e.g., Gardner, \& Clement, 1990; Gardner, 2010; MacIntyre, \& Gregersen, 2012).

Although before the year 2000 not many studies focused on formative assessment in a foreign language (FL) teaching, its facilitative nature had long been recognized by FL teachers and researchers (Ketabe, \& Ketabe, 2014; Rea-Dickins, \& Gardner, 2000). The elements of FA have been evident for a long time in commonly used portfolios designed for different age groups, which require from the learners to diagnose their strengths and weaknesses and self-assess their level of FL skills and subskills (Shohamy, 1995). What is, however, most vital for FL learning is the feedback received systematically and consistently from the instructors each lesson, so as to ensure the students if they are going the right direction. To learn a FL, the student needs to be provided with feedback as frequently as possible so as to receive verification of his/her FL tested hypotheses. Frequent formal summative assessment in this case can lead to inhibition and anxiety (Horwitz, 2017). On the other hand, leaving assessment till the end of a course and limiting it to a score can be expected to debilitate progress, due to depriving students of information about their FL use (Brown, 2004). As the noticing hypothesis states (Schmidt, 1990), a FL learner cannot progress if he/she does not notice the gap, i.e. see the difference between his/ her performance and its proper form. The role of feedback is to aid students in perceiving this difference, thus feedback seems to be a key requirement to progress in learning a FL (Brown, 2004; Harris, \& McCann, 1994). There is also no doubt nowadays that self-assessment, self-monitoring, reflection and autonomy can speed up the process of FL mastery (Czura, 2010). These are all building blocks of formative assessment. Besides the portfolio, these skills can be also developed by reflective diaries and journals. Finally, it seems worth adding that FA can be used to prevent the negative backwash effects of final formal tests (Ketabe, \& Ketabe, 2014).

\section{FORMATIVE ASSESSMENT IN POLAND}

Since the study reported in this paper was conducted among Polish learners, it seems worth adding that in Poland interest in FA was observed already in the 1990s, when a search for more contemporary methods of teaching that would facilitate learning and teaching by, among others, increasing students' motivation to learn and changing the approach to assessment was launched. One of the pilot studies, commissioned by the Polish Ministry of Education, aimed at verifying the benefits of introducing FA into teaching was conducted by institutions of teacher development (e.g. CODN - Central Institution of Teacher Development) in Warsaw in the years 2004/2005. It was inspired by the teaching practices in the UK and by the OECD report from 2005 entitled "Formative assessment. Improving learning in secondary classrooms" (Cho- 
roszczyńska, \& Kossakowska, 2007, p. 1). Among the key elements introduced in the project were clearly stated aims, cooperation with parents, using formative and summative assessment, feedback provision, colleague assessment and self-assessment.

On the basis of the quantitative and qualitative data gathered among teachers, students and parents it was concluded that FA develops teachers' reflection on their teaching practices. It was also found that cooperation among teachers using FA improved, consisting in sharing each other's experience and helping one another in the search for the best solutions. It was also the relationship between the principals and teachers that evidently improved (Choroszczyńska, \& Kossakowska, 2007).

From among the changes acknowledged by the teachers involved in the project was the new approach to giving feedback, whose content changed from focus on negative outcomes and weak sides of the students to positive observations. As the teachers claimed, introducing FA they were more interested in the strengths of their students and would search for ways of using the learners' potential for further successful learning and teaching. The change was visible not only according to the teachers but also students and parents participating in the project. Moreover, it was also the cooperation of the teachers with the parents of the students that became more systematic, being perceived as the source of vital information about the effectiveness of teaching. Most importantly, however, the teachers realised how their approach to lesson preparation changed. It consisted, for example, in a new approach to lesson planning, which would have very clear learning objectives, key questions, well-thought over manners and places of feedback giving, and better planning of time management. The lesson was believed to have a clearer structure with fluid transitions (Choroszczyńska, \& Kossakowska, 2007).

What is, however, even more vital were the changes in students' behaviour and way of thinking, which the answers to open questions provided by the teachers and students themselves suggested. The learners were said to become more open and to experience less anxiety in the classroom. They were also found to be more conscious and autonomous learners, being more responsible for their learning. They showed more initiative, were more active and seemed to be more motivated to learn. Although the teachers were very much aware of the fact that these changes could have been due to other extraneous variables, it was believed by them that it was also, if not first and foremost, the influence of introducing FA. Moreover, it was also the rapport between the students and teachers that changed, with the communication between the two being more sincere and the teacher being perceived by the student more as a partner and guide in their academic development.

Despite some difficulties in implementing FA, deriving mainly from the uniqueness of teaching culture deeply rooted in every country (e.g., being used to a different role of the teacher and to summative assessment in the case of Poland), the outcomes of the project were assessed very positively. For many years the concept of formative assessment has been present in Polish education 
and its use is required at all levels of education, i.e. from primary, through secondary, and ending with tertiary.

\section{METHODOLOGY}

In this section the study design is described in detail, starting with the research questions, followed by the presentation of participants of the study and the instrument used to collect the research data.

\section{RESEARCH QUESTIONS}

Having in mind the benefits of FA and the strong recommendation in Poland to use it, the main objective of the study was to find out if indeed formative assessment is applied during classes of English as a FL (EFL) run in Polish high schools. An attempt was made to verify the frequency of its use when teaching various FL skills and subskills in comparison to summative assessment. The quantitative data were then supplemented with qualitative data addressing students' opinions about the frequency, manner and type of assessment they received in high school. Consequently, the research questions were as follows:

1. How frequently is summative and formative assessment provided to Polish high school students during EFL classes?

2. Which FL skills and subskills are provided with the most and least frequent summative and formative assessment?

3. What type of tasks constitute the basis for provision of summative and formative assessment?

4. What are the students' opinions related to different types of assessment and feedback provision?

4a. Do they consider formative assessment to be frequent enough?

4b. Do they think any (sub)skills were neglected in terms of assessment and the feedback they were provided with?

4c. Do they believe the frequency, type of (sub)skills assessed, and type of assessment provided to them during secondary school education affected their attitudes towards learning English, rapport with the teacher, and success in FL learning?

\section{PARTICIPANTS}

To answer the research questions presented above, 106 first-year students of the University of Wrocław and Technical University of Wrocław were invited to take part in a questionnaire-based study. The participants of the former affiliation (64\%) were students of the Institute of English Studies, $67 \%$ of whom attended day studies, and 33\% - extramural studies. The participants of the 
latter institute constituted $46 \%$ of the respondents. They were studying 11 different majors, such as Automation and Robotics, Mathematics and Statistics, IT, Biomedical Engineering, Marketing and Management, Energetics, Quantum Engineering, Tectonics, Chemical and Process Engineering, and Architecture. $94 \%$ of the respondents graduated comprehensive high schools (liceum), $4 \%$ - technical schools, and 1\% - an art high school. They all passed the final high school examination (Matura), among others in English, in the following years: 2017 (43\%), 2016 (35\%), 2015 (15\%), and 2014\% (6\%). Although the participants were all students of one of the two universities in Wrocław, it is most vital to clarify that they all attended different high schools located in various towns and cities in Poland, mainly the southern and central regions of the country. While $38 \%$ of the respondents were graduates of various high schools in the city of Wrocław, the remaining 62\% came from 35 different places, for example: Bielsko-Biała, Częstochowa, Dzierżoniów, Kłodzko, Legnica, Nowy Sącz, Opole, Ostrów Wielkopolski, Rawicz, Pszczyna, Turek, Wałbrzych, Zgorzelec, Zielona Góra. Collecting data from students graduating so many different schools situated in numerous places seems to allow for stating what the general tendencies related to the inquired matter in Poland are.

\section{INSTRUMENT}

The data were collected with the use of an anonymous questionnaire written in the learners' mother tongue. To ensure its clarity, before the final version was produced its initial form was piloted among 15 MA English majors, which resulted in reformulating a few questions and changing their order. Filling out the proper questionnaire took approximately 15 minutes and completing it was optional. It was distributed to the participants during either a lecture of American literature (in the case of English majors) or one of their regular classes of English (in the case of English non-majors).

The survey opened with instructions, followed by a few socio-demographic questions inquiring about the respondents' university attended, major, type of school completed, and place and year of taking the final high school exam. The main body of the instrument consisted of two main types of questions. The first type contained 4 questions based on an 8-point Likert scale and addressed the following issues:

1/ frequency of being provided with summative assessment in reference to different (sub)skills: "How often was your progress in developing different subskills in English assessed (with a credit)? Provide a digit next to each skill."

2/ frequency of being provided with formative assessment in reference to different (sub)skills: "How often were you provided with feedback - received information from your teacher about your FL learning strengths and weaknesses, areas to be worked on, shown how to work on them, encouraged and shown how to self-assess your skills, without being given a credit - in the case of the following skills? Provide a digit next to each skill." 
3/ frequency of different techniques/tasks being used by the participants' teachers to verify their progress in developing various FL (sub)skills, using summative assessment: "How often were the following technique/tasks used to evaluate your progress in different English subskills, with the use of a credit? Provide a digit from 1-8 next to each subskill."

4/ frequency of different techniques/tasks being used by the participants' teachers to provide formative assessment in reference to developing various FL (sub)skills: "How often were the following technique/tasks used to provide you with feedback, i.e. information about the matters you deal well with, areas to be worked on, demonstration how to work on them, encouragement and demonstration how to self-assess your skills, without being given a credit? Provide a digit from 1-8 next to each technique/task."

In the first two questions, the participants were to write a digit in reference to each skill and subskill into a table, as presented below.

Table 1.

The table used by the respondents to mark the frequency of being provided with summative and formative assessment

\begin{tabular}{lcc}
\hline & Final (Matura) form & Forms I-III/IV \\
\hline Example. Reading comprehension & 3 & 5 \\
Grammar & & \\
Vocabulary & & \\
Pronunciation & & \\
Speaking/communication skills & & \\
Writing (e.g. e-mails, essays) & & \\
Reading comprehension & & \\
Listening comprehension & & \\
\hline
\end{tabular}

The digits from 1 to 8 , which the respondents could choose from meant the following:

8. Almost every lesson

7. About once a week

6. About once-twice a month

5. About 2-3 times a semester

4. About once a semester

3. Occasionally, once-twice a year

2. Occasionally, once-twice within a few years

1. I can't remember being assessed for this subskill

An analogous table with the same 8-point Likert scale was used in the case of Questions 3 and 4. This time, however, instead of (sub)skills, a few tasks or techniques related to different (sub)skills were provided, which could be applied by teachers to give both summative and formative assessment in these areas. These were, for example:

- translation of sentences and words,

- completing a sentence with the verb in the proper form, 
- answering comprehension check questions referring to a written text,

- dictation,

- filling in gaps with missing words (nouns, adjectives, verbs, etc.),

- answering questions verifying listening skills,

- discussion, role play, presentation or other speaking tasks to assess the level of intelligibility,

- reading a text or list of words to focus on the pronunciation of words,

- marking stressed syllables in words.

It is important to clarify that there were more items provided in Questions 3 and 4 referring to pronunciation tasks that could be used to provide formative and summative assessment in the case of this subskill. This is due to the fact that the questionnaire's main aim was to gather information about formative assessment specifically in pronunciation teaching, which another article is devoted to. Although the items concerning assessment of all skills and subskills were used mainly to reduce the subject expectancy effect, they provide us with valuable and reliable information about formative assessment used for teaching all FL (sub)skills.

As Table 1 displays, the participants' task was to specify the frequency of experiencing formative and summative assessment separately in the case of forms I-III and the final (Matura) form. This is due to the fact that it was expected differences might appear depending upon the form, taking into account the possibility of backwash effect of the coming final examination.

When analysing the quantitative data, the frequency of occurrence of particular digits from 1 to 8 in the tables following Questions 1- 4 was computed. The outcomes are presented in the subsection below.

What followed the four closed questions were 5 questions with a 4-point Likert scale, supplemented in each case with an open-ended question. Among them were the following ones:

1. Were any subskills listed in Q.1 and Q.2 assessed with a credit too rarely at your high school English classes?

$\square$ Definitely yes

$\square$ Yes

$\square$ No

$\square$ Definitely not

Which subskills were they?

2. Were you given enough feedback (without credits) on the progress of all the English subskills?

$\square$ Definitely yes

$\square$ Yes

$\square$ No

$\square$ Definitely not

If not, which subskill(s) did you receive too little feedback on?

Figure 1.

Examples of open-ended questions used in the questionnaire. 
Analogously, the next question (Q.7) inquired about whether the frequency, manner of assessment and the choice of assessed skills affected the students' success in learning English, supplemented by the open questions: "Why? In the case of which skill(s) was this?" Question 8 asked: "Did the frequency and manner of giving feedback, assessment and the choice of assessed skills affect your attitude towards learning English? Why? Which skill(s) did it concern?" Finally, the last question addressed the problem of assessment and feedback giving shaping the rapport with the teacher, i.e.: "Did the frequency and manner of giving feedback, assessment and the choice of assessed subskills affect your rapport with the English teacher? Why? The assessment of which skills do you think that concerned?"

The analysis of the answers to the questions with the Likert scale focused again on computing the frequency of the four responses chosen by the participants. In the case of the answers to open questions, codes to the provided responses were suggested and common tendencies were looked for. The outcomes of the analyses are presented in the subsection below.

\section{PRESENTATION AND DISCUSSION OF RESULTS}

In this section, the outcomes of the study are presented and briefly discussed, starting with a focus on quantitative data, followed by an analysis of qualitative outcomes.

\section{QUANTITATIVE DATA}

The first set of data allows us to see how frequently the participants of the study were assessed formally with the use of a credit for their progress in learning different FL skills and subskills. The outcomes in the case of FL subskills, i.e., grammar, vocabulary and pronunciation, are presented in Table 2. The most popular answers have been marked in bold to make them more visible.

\section{Table 2.}

Frequency of summative assessment provision in the case FL subskills

\begin{tabular}{ccccccc}
\hline & $\begin{array}{c}\text { Gram. } \\
\text { final f. }\end{array}$ & f. I-III/IV & $\begin{array}{c}\text { Voc. } \\
\text { final f. }\end{array}$ & f. I-III/IV & $\begin{array}{c}\text { Pron. } \\
\text { final f. }\end{array}$ & f. I-III/IV \\
\hline $\mathbf{1}$ & $0 \%$ & $2 \%$ & $2 \%$ & $4 \%$ & $34 \%$ & $36 \%$ \\
$\mathbf{2}$ & $0 \%$ & $1 \%$ & $2 \%$ & $1 \%$ & $6 \%$ & $5 \%$ \\
$\mathbf{3}$ & $14 \%$ & $5 \%$ & $1 \%$ & $2 \%$ & $8 \%$ & $9 \%$ \\
$\mathbf{4}$ & $7 \%$ & $8 \%$ & $1 \%$ & $6 \%$ & $13 \%$ & $12 \%$ \\
$\mathbf{5}$ & $\mathbf{2 6} \%$ & $\mathbf{3 4} \%$ & $\mathbf{2 3} \%$ & $\mathbf{2 7} \%$ & $10 \%$ & $11 \%$ \\
$\mathbf{6}$ & $\mathbf{3 5} \%$ & $\mathbf{3 4} \%$ & $40 \%$ & $\mathbf{3 8} \%$ & $6 \%$ & $12 \%$ \\
$\mathbf{7}$ & $\mathbf{1 3} \%$ & $\mathbf{1 4} \%$ & $\mathbf{2 2} \%$ & $\mathbf{1 5} \%$ & $8 \%$ & $6 \%$ \\
$\mathbf{8}$ & $5 \%$ & $2 \%$ & $10 \%$ & $8 \%$ & $14 \%$ & $8 \%$ \\
\hline
\end{tabular}

Note: Gram. - grammar; Voc. - vocabulary, Pron. - pronunciation; f. - form 
Analysing the outcomes displayed in all the tables, it seems worth remembering that high percentages in the rows from 1 to 3 ought to be considered as alarming since they denote the lack of or just occasional provision of assessment in FL (sub)skills. When the frequency of formal assessment in the case of grammar and vocabulary is concerned, it seems that it was usually provided to the participants twice or three times a semester, about once-twice a month or even once a week. The subskill that evidently stands out is pronunciation, whose assessment with a credit as many as $34 \%$ to $36 \%$ of the participants do not recall having ever received during their secondary school education.

Table 3 offers data in reference to summative assessment of FL skills, such as speaking, listening, reading and writing.

\section{Table 3.}

Frequency of summative assessment provision in the case of FL skills

\begin{tabular}{ccccccccc} 
& $\begin{array}{c}\text { Spk. } \\
\text { final f. }\end{array}$ & f. I-III/IV & $\begin{array}{c}\text { Writ. } \\
\text { final f. }\end{array}$ & f. I-III/IV & $\begin{array}{c}\text { Rd. } \\
\text { final f. }\end{array}$ & f. I-III/IV & final f. & f. I-III/IV \\
\hline $\mathbf{1}$ & $10 \%$ & $\mathbf{1 8} \%$ & $4 \%$ & $12 \%$ & $8 \%$ & $9 \%$ & $8 \%$ & $11 \%$ \\
$\mathbf{2}$ & $7 \%$ & $6 \%$ & $0 \%$ & $1 \%$ & $1 \%$ & $2 \%$ & $3 \%$ & $3 \%$ \\
$\mathbf{3}$ & $8 \%$ & $13 \%$ & $5 \%$ & $10 \%$ & $6 \%$ & $8 \%$ & $7 \%$ & $8 \%$ \\
$\mathbf{4}$ & $\mathbf{1 5 \%}$ & $\mathbf{1 6} \%$ & $14 \%$ & $15 \%$ & $10 \%$ & $15 \%$ & $9 \%$ & $12 \%$ \\
$\mathbf{5}$ & $\mathbf{1 8} \%$ & $\mathbf{1 8} \%$ & $\mathbf{3 2} \%$ & $30 \%$ & $\mathbf{2 5} \%$ & $\mathbf{2 3} \%$ & $\mathbf{2 4} \%$ & $\mathbf{2 2 \%}$ \\
$\mathbf{6}$ & $12 \%$ & $11 \%$ & $\mathbf{3 5 \%}$ & $22 \%$ & $17 \%$ & $\mathbf{2 1} \%$ & $\mathbf{2 1 \%}$ & $\mathbf{2 1 \%}$ \\
$\mathbf{7}$ & $11 \%$ & $6 \%$ & $8 \%$ & $8 \%$ & $17 \%$ & $13 \%$ & $17 \%$ & $16 \%$ \\
$\mathbf{8}$ & $\mathbf{1 8} \%$ & $12 \%$ & $2 \%$ & $1 \%$ & $16 \%$ & $9 \%$ & $12 \%$ & $7 \%$ \\
\hline
\end{tabular}

Note: Spk. - speaking, Writ. - writing, Rd. - reading, List. - listening; f. - form

This time, the most popular answers were 4, 5 and 6, which denotes that the majority of the subjects received formative assessment of these skills one, twice or three times a semester, or once-twice a month.

Table 4.

Frequency of formative assessment provision in the case of FL subskills

\begin{tabular}{ccccccc}
\hline & $\begin{array}{c}\text { Gram. } \\
\text { final f. }\end{array}$ & f. I-III/IV & $\begin{array}{c}\text { Voc. } \\
\text { final f. }\end{array}$ & f. I-III/IV & $\begin{array}{c}\text { Pron. } \\
\text { final f. }\end{array}$ & f. I-III/IV \\
\hline $\mathbf{1}$ & $13 \%$ & $16 \%$ & $16 \%$ & $\mathbf{1 9} \%$ & $\mathbf{2 5 \%}$ & $\mathbf{2 8 \%}$ \\
$\mathbf{2}$ & $8 \%$ & $6 \%$ & $4 \%$ & $6 \%$ & $4 \%$ & $5 \%$ \\
$\mathbf{3}$ & $12 \%$ & $14 \%$ & $13 \%$ & $12 \%$ & $12 \%$ & $9 \%$ \\
$\mathbf{4}$ & $11 \%$ & $14 \%$ & $9 \%$ & $10 \%$ & $13 \%$ & $15 \%$ \\
$\mathbf{5}$ & $11 \%$ & $14 \%$ & $10 \%$ & $15 \%$ & $8 \%$ & $10 \%$ \\
$\mathbf{6}$ & $\mathbf{2 0} \%$ & $16 \%$ & $\mathbf{2 5} \%$ & $\mathbf{1 9} \%$ & $11 \%$ & $12 \%$ \\
$\mathbf{7}$ & $9 \%$ & $11 \%$ & $9 \%$ & $11 \%$ & $8 \%$ & $7 \%$ \\
$\mathbf{8}$ & $15 \%$ & $8 \%$ & $13 \%$ & $8 \%$ & $\mathbf{2 0} \%$ & $13 \%$ \\
\hline \multicolumn{7}{r}{ Note: Gram. - grammar; Voc. - vocabulary, Pron. - pronunciation; f. - form }
\end{tabular}


The second set of data reports the frequency of formative assessment being used in the EFL classroom, represented by feedback provision, consisting in showing the students their strengths and weaknesses, suggesting FL areas for future focus, strategies worth trying to improve particular (sub)skills and encouraging self-assessment. Tables 4 and 5 show how often, according to the respondents, formative assessment was provided to them in reference to the three subskills and four skills.

This time the distribution of responses is evidently different from the distribution of answers found in summative assessment. Although in the case of grammar and vocabulary digit 6 was chosen most often by the respondents, which stands for assessment being provided once-twice a month, almost half of the participants marked digits 1-4, which denoted occasional provision of feedback with $13 \%$ to $19 \%$ declaring not having received such feedback at all when learning English at high school. Just as in the case of summative assessment, it seems that pronunciation scores stand out. Although $20 \%$ of the respondents declared that in the final form their formative assessment of this subskill took place almost every class, as many as $25 \%$ to $28 \%$ of the subjects declared not having been assessed for this subskill at all during their secondary school education.

Finally, Table 5 offers a look at how frequently the participants received feedback while practising the four skills. As the outcomes display, here the scores are evidently alarming, with as many as from $20 \%$ to $27 \%$ students, depending upon the skill, acknowledging not having been offered formative assessment without a credit ever during their secondary school education.

Table 5.

Frequency of formative assessment provision in the case of FL skills

\begin{tabular}{ccccccccc}
\hline & $\begin{array}{c}\text { Spk. } \\
\text { final f. }\end{array}$ & f. I-III/IV & $\begin{array}{c}\text { Writ. } \\
\text { final f. }\end{array}$ & f. I-III/IV & final f. & f. I-III/IV & final f. & f. I-III/IV \\
\hline $\mathbf{1}$ & $\mathbf{2 0} \%$ & $\mathbf{2 5 \%}$ & $22 \%$ & $\mathbf{2 7} \%$ & $\mathbf{2 3} \%$ & $\mathbf{2 5 \%}$ & $\mathbf{2 2 \%}$ & $\mathbf{2 5 \%}$ \\
$\mathbf{2}$ & $4 \%$ & $5 \%$ & $2 \%$ & $5 \%$ & $4 \%$ & $6 \%$ & $6 \%$ & $4 \%$ \\
$\mathbf{3}$ & $12 \%$ & $8 \%$ & $12 \%$ & $13 \%$ & $15 \%$ & $13 \%$ & $12 \%$ & $12 \%$ \\
$\mathbf{4}$ & $10 \%$ & $10 \%$ & $14 \%$ & $14 \%$ & $11 \%$ & $9 \%$ & $13 \%$ & $13 \%$ \\
$\mathbf{5}$ & $11 \%$ & $\mathbf{2 0} \%$ & $19 \%$ & $19 \%$ & $17 \%$ & $20 \%$ & $16 \%$ & $17 \%$ \\
$\mathbf{6}$ & $18 \%$ & $14 \%$ & $\mathbf{2 4} \%$ & $15 \%$ & $12 \%$ & $11 \%$ & $15 \%$ & $13 \%$ \\
$\mathbf{7}$ & $8 \%$ & $6 \%$ & $4 \%$ & $3 \%$ & $8 \%$ & $8 \%$ & $7 \%$ & $8 \%$ \\
$\mathbf{8}$ & $17 \%$ & $11 \%$ & $4 \%$ & $4 \%$ & $10 \%$ & $8 \%$ & $9 \%$ & $7 \%$ \\
\hline
\end{tabular}

Note: Spk. - speaking, Writ. - writing, Rd. - reading, List. - listening; f. - form

It seems worth adding that a clear tendency can be observed when comparing the provision of both summative and formative assessment in earlier forms (I-III) and the final form. It appears to be more frequent in the case of the latter, which leads directly to the Matura examination. It may be hypothesised that this is due to the backwash effect. There is, however, no doubt that it is already in the earlier classes that students should receive regular feedback on their learning. 
Where the third research question is concerned, an analogous pattern was observed with formative assessment being much less frequently offered when performing the tasks mentioned than summative assessment. As could be expected from the data presented earlier, the least frequent summative assessment, i.e. answers 1 to 3 marked from $45 \%$ to $72 \%$ of the respondents depending on the form, was declared in the case of tasks related to pronunciation (discussion, role play, presentation or other speaking tasks to assess the level of intelligibility, reading a text or list of words to focus on pronunciation of words, marking stressed syllables in words). The data were even less satisfying in the case of formative assessment related to pronunciation. Digit 1, standing for "I can't remember being assessed for this subskill" was marked by $24 \%$ (final form) and 30\% (forms I-III) of the participants in the case of the tasks allowing to give feedback on intelligibility, and by $31 \%$ (final form) and 34\% (forms I-III) in the case of the tasks that could be used to provide feedback on word pronunciation. What is, however, most striking is the number of participants who declared never having received any feedback related to stressing syllables in words, which equalled $86 \%$ (final form) and $85 \%$ (forms I-III). Such outcome may be due to pronunciation being generally neglected in teaching, for which there are several reasons and which constitutes a vital problem not only in Poland (see Derwing, \& Munro, 2015; Szpyra-Kozłowska, 2015).

The most popular tasks (digits 5 to 8 chosen by from $65 \%$ to $70 \%$ of respondents) used for assessing students formally proved to be completing a sentence with the verb in the proper form, filling in gaps with missing words, and translation of sentences and words. The second common choice was answering comprehension check questions referring to a written text and to a recording (digits 5 to 8 chosen by from $43 \%$ to $65 \%$ of respondents). Unfortunately, the same tasks were not that popular any more as a basis for providing feedback to students, with digits 5 to 8 being chosen by not more than $35 \%$ of the participants.

\section{QUALITATIVE DATA}

As mentioned in the subsection describing the instrument, the open questions allowing us to get to know the opinions of the respondents on assessment were initiated by simple introductory questions. One of them inquired whether the participants were content about the amount of assessment they were provided with. As many as $68 \%$ believed the assessment was too rare, with $31 \%$ choosing the option "Definitely yes" and 31\% - "Yes."

When asked in the next question to enumerate the (sub)skills they felt were assessed too rarely, the most common response provided by $92 \%$ of the participants was pronunciation. The next (sub)skills that students believed were not evaluated enough frequently were as follows: speaking (chosen by 51\%), listening (chosen by $7 \%$ ) and writing (chosen by $5 \%$ of the respondents). 
An analogous distribution of answers can be observed in the case of Question 6, addressing the matter of potentially neglected formative assessment. $61 \%$ of the participants believed that the feedback they had received in high school was too scarce. More specifically, while $7 \%$ of the respondents provided the answer "No" to the question "Were you given enough feedback (without credits) on the progress of all the English subskills?", as many as 54\% declared this was definitely not the case. When the participants were asked to share their opinion about which (sub)skill(s) they thought they received too little feedback on, the most popular answer they gave was again pronunciation $(75 \%)$. The second FL skill neglected in terms of feedback provision was speaking (19\%), followed by listening (11\%) and writing (11\%).

The quantitative data were supported by qualitative data. Among them were direct claims about being provided with limited feedback, e.g.:

"Vocabulary, pronunciation and writing were only assessed by a credit, which didn't tell me anything about my weaknesses and how to deal with them."

"We received too little feedback on all subskills. Actually, we didn't get any info on our strengths and weaknesses or how to work on the aspects we had problems with."

"The information about my skills was provided only in the form of grades."

"I definitely received too little feedback on pronunciation and my progress and its lack in writing."

Furthermore, $58 \%$ of the subjects agreed that frequency and manner of assessment and the choice of assessed subskills affected their success in learning English. 79\% of the respondents thought there were serious negative consequences of having been provided with so little feedback on their progress, particularly when pronunciation (41\%) and speaking skills (38\%) are concerned. A disappointment was expressed from not being informed about the necessity to improve certain skills. The students were also worried that now they needed to work harder to eliminate the errors ingrained in them due to lack of teachers' reaction to their performance. Among the responses were the following ones: "I had no idea my pronunciation needed to be improved because I was never assessed nor received any feedback on this aspect," "The areas of the language that were not assessed were automatically ignored by me in conscious studying," "Nobody checked our pronunciation. Now it's more difficult to get rid of bad habits of pronouncing different words" or "No feedback on speaking skills resulted in my very poor abilities to communicate," and "My pronunciation is terrible because we were focusing on reading and vocabulary."

Finally, it is important to add that $52 \%$ of the learners believed the frequency, manner and choice of assessed FL skills shaped their attitude towards the teacher. The responses signalled that negative rapport was caused when the feedback was not constructive, unclear and unfair, when the teacher did not show respect towards the student, the tests were too difficult or appeared too frequently. Among the statements offered by the respondents were the following: 
"A teacher relying only on grades and tests is wasting class time and discouraging students from learning."

"I liked and respected the teacher who assessed and gave me feedback on my speaking skills and pronunciation. I didn't like the teacher who focused only on grammar."

"I disliked one of my previous teachers for her focusing on and assessing constantly areas I was not keen on."

"I really liked my teacher; he would draw lots of attention to speaking, gave us lots of feedback on our mistakes and suggested how things could've been expressed differently."

\section{CONCLUSIONS}

As several educational specialists stress, both summative and formative assessment are necessary in the process of education. Many studies have proven the benefits of formative assessment, which is recommended to be used on a daily basis (e.g. Black, \& Wiliam, 1998a). This seems to be very true particularly in the case of FL learning, a process in which the student needs constant and immediate feedback on whether he/she is going in the right direction, positive remarks lowering anxiety and raising motivation, and guidance on learning strategies and how to become an autonomous learner. The data reported in this study suggest that formative assessment is neglected by FL high school teachers, whose negative consequences are evident to the learners. Ignoring both summative and formative assessment was visible in this study in the case of pronunciation.

It must be made clear that the research has a few limitations, which may have affected the achieved outcomes. Among them is the relatively small sample. It may be worth replicating the study not only with more learners but also an improved instrument in which the functions of formative assessment could be addressed separately. Finally, it would be interesting to triangulate the data, by gathering information among the teachers and finding out why formative assessment is avoided in FL classrooms. Despite the limitations of the study, the results may be a basis for considering devoting more time to formative and summative assessment during both pre- and in-service teacher training courses. The data also evidently show that more training among teachers is needed on pronunciation teaching and assessment.

\section{REFERENCES}

1. Alderson, J. C., Brunfaut, T., \& Harding, L. (2015). Towards a theory of diagnosis in second and foreign language assessment: insights from professional practice across diverse fields. Applied Linguistics, 36, 2, 236-260.

2. Assessment Reform Group. (2007). Assessment for learning. Retrieved from https://www.nuffieldfoundation.org/assessment-reform-group. 
3. Atkin, J., Black, P., \& Coffey, J. (Eds.) (2005). Classroom assessment and the national science education standards. Committee on Classroom Assessment and the National Science Education Standards, Center for Education, National Research Council. Washington, DC: National Academy Press.

4. Bachman, L. F. (1990). Fundamental considerations in language testing. Oxford: Oxford University Press.

5. Bachman, L. F. (2005). Building and supporting a case for test use. Language Assessment Quarterly, 2, 1-34.

6. Bachman, L. F., \& Palmer, A. (1996). Language testing in practice: Designing and developing useful language tests. Oxford: Oxford University Press.

7. Barbosa, M., \& Beserra, L. (2015). Formative assessment in the foreign language classroom. Brazilian English Language Teaching Journal, 6 (1), 100-109.

8. Black, P., \& Wiliam, D. (1998a). Assessment and classroom learning. Assessment in Education, 5, 7-73.

9. Black, P., \& Wiliam, D. (1998b). Inside the black box: Raising standards through classroom assessment. Phi Delta Kappan, 80, 139-144.

10. Black, P., \& Wiliam, D. (2006). Assessment for learning in the classroom. In: J. Gardner (Ed.), Assessment and learning: Theory, practice and policy (pp. 9-25). London: Sage.

11. Brookhart, S. M., \& Durkin, D. (2003). Classroom assessment, student motivation, and achievement in high school social studies classes. Applied Measurement in Education, 16, 27-54.

12. Brown, H. D. (2004). Language assessment: principles and classroom practices. New York: Pearson Education.

13. Butler Y., \& Jiyoon, L. (2010). The effects of self-assessment among young learners of English. Language Testing, 27, 5-31.

14. Chickering, A. W. \& Gamson, Z. F. (Eds.). (1991). Applying the seven principles for good practice in undergraduate education. San Francisco, CA: Jossey-Bass.

15. Choroszczyńska, M., \& Kossakowska, B. (2007). Czy doświadczenia polskie w zakresie wdrażania oceniania kształtujacego sa OK? [Is Polish experience in implementing formative assessment OK?] Retrieved from http:/ / docplayer.pl/12822499-Czy-doswiadczenia-polskie-w-zakresiewdrazania-oceniania-ksztaltujacego-sa-ok.html.

16. Crooks, T. (1988). The impact of classroom evaluation on students. Review of Educational Research, 58, 438-481.

17. Czura, A. (2010). The influence of assessment type on the development of autonomy in lower secondary school learners (Unpublished doctoral dissertation). University of Wrocław, Poland.

18. Derwing, T. M., \& Munro, M. J. (2015). Pronunciation fundamentals: Evidence-based perspectives for L2 teaching and research. Amsterdam: John Benjamins.

19. Fernandes, D. (2011). Avaliar para melhorar as aprendizagens: Análise e discussão de algumas questões essenciais. [Evaluate to improve learning: Analysis and discussion of some key issues.] In: I. Fialho, \& H. Salgueiro (Eds.), Turma Mais e sucesso escolar: Contributos teóricos e práticos, (pp. 81-107). Évora: Centro de Investigação em Educação e Psicologia da Universidade de Évora.

20. Fontana, D., \& Fernandes, M. (1994). Improvements in mathematics performance as a consequence of self-assessment in Portuguese primary school pupils. British Journal of Educational Psychology, 64, 404-417.

21. Harlen, W., \& Winter, J. (2004). The development of assessment for learning: Learning from the case of science and mathematics. Language Testing, 21, 390-408.

22. Harris, M., \& McCann, P. (1994). Assessment (Handbook for the English classroom). Oxford: Heinemann Publishers.

23. Horwitz, E. K. (2017). On the misreading of Horwitz, Horwitz, and Cope (1986) and the need to balance anxiety research and the experiences of anxious language learners. In: C. Gkonou, M. Daubney, \& J. M. Dewaele (Eds.), New insights into language anxiety: Theory, research and educational implications (pp. 31-47). Bristol: Multilingual Matters.

24. Gardner, J. 2006. Assessment and learning. London: Sage.

25. Gardner, C. R. (2010). Motivation and Second language acquisition: The psycho-educational Model. New York: Peter Lang Publishing.

26. Gardner, C. R., \& Clément, R. (1990). Social psychological perspectives on second language 
acquisition. In: H. Giles, \& W. P. Robinson (Eds.), Handbook of language and social psychology (pp. 495-517). London: Wiley.

27. Gattullo, F. (2000). Formative assessment in ELT primary (elementary) classrooms: an Italian case study. Language Testing, 17 (2), 278-288.

28. Geeslin, K. (2003). Student self-assessment in the foreign language classroom: The place of authentic assessment instruments in the Spanish language classroom. Hispania, 86, 857-868.

29. Ketabi, S., \& Ketabi, S. (2014). Classroom and formative assessment in second/foreign language teaching and learning. Theory and Practice in Language Studies, 4(2), 435-440.

30. Lewy, A. (1990). Formative and summative evaluation. In: Walberg, H. \& Haertel, G. (Eds.), The international encyclopedia of educational evaluation (pp. 26-28). Oxford, England; New York: Pergamon Press.

31. MacIntyre, P. D., \& Gregersen, T. (2012). Emotions that facilitate language learning: The positive-broadening power of the imagination. Studies in Second Language Learning and Teaching, 2, 193-213.

32. McDonald, B., \& Boud, D. (2003). The impact of self-assessment on achievement: The effects of self-assessment training on performance in external examinations. Assessment in Education, 10, 209-220.

33. Nitko, A. J. (1993). Designing tests that are integrated with instruction. In: Linn, R. L. (Ed.), Educational measurement (pp. 447-474). Phoenix, Arizona: Oryx Press.

34. Radford, B. W. (2015). The effect of formative assessments on language performance (Unpublished doctoral dissertation). Birmingham Young University, Provo, USA.

35. Rea-Dickins, P., \& Gardner, Sh. (2000). Snares and silver bullets: disentangling the construct of formative assessment. Language Testing, 17(2), 215-243.

36. Schmidt, R. (1990). The role of consciousness in second language learning. Applied Linguistics, 11, 129-158.

37. Shohamy, E. (1995). Performance assessment in language testing. Annual Review of Applied Linguistics, 15, 188-211.

38. Shohamy, E. (2001). The power of tests. London: Longman.

39. Stiggins, R. (2007). Assessment through the student's eyes. Educational Leadership, 64(8), 22-26.

40. Szpyra-Kozłowska, J. (2015). Pronunciation in EFL Instruction: A Research-Based Approach. Bristol, Buffalo, Toronto: Multilingual Matters.

41. Triggs, P., Weeden, P., Winter, J., \& Broadfoot, P. (2000). The LEARN project Phase 2: Developing assessment in the primary school project report (University of Bristol Graduate School of Education CLIO Centre for Assessment Studies). Report for the Qualifications and Curriculum Authority. Retrieved from http://www.qca.org.uk/qca_4490.aspx.

42. Van de Watering, G., \& Van der Rijt (2006). Teachers' and students' perceptions of assessments: A review and a study into the ability and accuracy of estimating the difficulty levels of assessment items. Educational Research Review, 1, 133-147. 